individuals who are excited about their research are also engaging and dynamic teachers who incorporate innovative tools into their courses. I was disappointed that Seymour and Hewitt did not examine the underlying reasons for the students' perceptions and the accuracy of the students' criticism.

Talking about Leaving does not make easy reading - I do not recommend it for reading lying down or at the beach. The density of information is extremely high and I found that I needed to take notes and highlight key points in the text to be able to extract the essence of the conclusions. The text is also rife with quotations from students interviewed for the study which were intended to exemplify the point. The effect is to distract the reader from the train of thought in the surrounding text, and I found myself needing to re-read previous material to develop a conceptual thread.

Nevertheless, this is a good reference text for those interested in improving undergraduate curricula in science and engineering. The many quotations and anecdotes will be useful to anyone who needs to illustrate problems in science and engineering education.

Cynthia M. Friend is in the Department of

Chemistry, Harvard University, Cambridge,

Massachusetts 02138, USA.

\section{You can see right through me}

\author{
Naked to the Bone: Medical Imaging \\ in the Twentieth Century \\ by Bettyann Holtzmann Kevles \\ Rutgers University Press: 1997. Pp. 378. \\ $\$ 35.95$
}

\section{John Mallard}

The ability to see through our bodies has shown us rather more these past one hundred years or so since $\mathrm{X}$-rays and radioactivity were discovered than we may have realized. Until I read this book by Bettyann Kevles I had no idea that the discovery of Xrays was the inspiration for $\mathrm{H}$. G. Wells to write The Invisible Man, or that Maurice Ravel and George Gershwin had brain abnormalities, which were revealed by the use of X-ray contrast agents.

The book is part of a series that aims to convey "the technical and human dimensions of the subject; the invention and effort entailed in devising the technologies; and the comforts and the stresses they have introduced into contemporary life". These goals are achieved very well, as you might expect in a book by a journalist with a newspaper science column who has won an award for the best science book for young adults and teaches science to art students.

\title{
Umpteenth editions and other revisions
}

\section{Behavioural Ecology: An Evolutionary} Approach. Fourth edition

by J.R. Krebs and N.B. Davies

Blackwell Science, $£ 26.50, \$ 49.95$

Like the previous three editions of this classic behavioural ecology text, this fourth edition brings together a completely new set of chapters to provide an up-to-date picture of the subject. When T.R. Birkhead reviewed the second edition in Nature 314, 37 (1985), he wrote: "All in all this is an excellent text. It is well produced, clearly written and provides plenty to think about". This latest edition maintains these high standards.

\section{The Evolution of the Soul. Revised edition}

by Richard Swinburne

Oxford University Press, $£ 40, \$ 75$ ( $h b k$ ); $£ 15.99$, $\$ 24.99$ (pbk)

Richard Swinburne argues that we can only make sense of the interdependence of mental states and brain states by supposing that "mental states are states of a soul, a mental substance in interaction with the body". When D.M. MacKay reviewed the first edition in Nature 323, 679 (1986), he wrote: "I do not know of a better or more persuasive statement of the case for dualist interactionism in the sense he defines".

\section{Animal Physiology: Adaptation and Environment. Fifth edition}

by Knut Schmidt-Nielsen

Cambridge University Press, $£ 24.95, \$ 47.95$

This highly acclaimed undergraduate textbook for courses in physiology and zoology was

There are very good numbered notes for each chapter, and a most interesting bibliography separated into history, culture and society; law and policy; fiction; and medicine, science and technology.

The first part of the book, dealing with the first half-century of X-rays, is the most reliable. However, in the introduction, Wilhelm Röntgen is described as "a somewhat pedestrian German physicist" - this is later dispelled when "Röntgen's genius" is explained, and I should think so, too! Although it is brought out that he did not patent his discovery, it is not mentioned that he died a pauper. Philipp Lenard's jealousy is well described, the atmosphere of the times is captured, and the early days of X-ray tomography, before computed tomography, are well discussed.

The author seems to have lost her way a bit in the second half, which deals with the newer imaging methods of computed tomography, magnetic resonance imaging, positron emission tomography and ultrasound, in that order. It is out of sequence, however, as nuclear medicine imaging, including that with computed tomography, came before X-ray computed first published in 1975. This fifth edition takes into account recent developments in the field, particularly in movement and biomechanics.

\section{Optima for Animals. Revised edition}

by R. McNeill Alexander

Princeton University Press, $\$ 60, £ 45(\mathrm{hbk})$; $\$ 24.95$, $£ 18.95$ (pbk). Distributed in the UK by Wiley

The optimizing processes of evolution and learning have shaped the structures, movements, behaviour and life histories of animals. Here they are explained for the undergraduate, with the mathematics kept as simple as possible.

\section{Biogeochemistry: An Analysis of} Global Change. Second edition

by William $\mathrm{H}$. Schlesinger

Academic Press, $\$ 49.95, £ 34.95$

This undergraduate text covers the effects of life on the chemistry of the Earth. It has been updated to take into account the rapid changes in our understanding of the way the Earth's systems function.

\section{A Dictionary of Genetics. Fifth edition}

by Robert C. King and William D. Stansfield Oxford University Press, $£ 35$, \$45 (hbk); $£ 19.95$, $\$ 24.95(p b k)$

From A to zymogen granules, the fifth edition of this dictionary contains over 6,500 definitions relevant to geneticists. It also has a classification of living organisms, a section on domesticated species, and a chronology of over 400 years of genetic research.

tomography, and magnetic resonance imaging came after nuclear medicine imaging and positron emission tomography. The "Timeline" table at the end of the book helps appreciation of the timeflow and the parallel developments in the various

\section{IMAGE UNAVAILABLE FOR COPYRIGHT REASONS}

Hand in marriage: Röntgen used his wife's hand for this first X-ray image of a human. 